\title{
Nonsurgical Removal of Overextended Gutta-Percha Root Canal Filling in a Permanent Maxillary Central Incisor with Apical Root Resorption - A Case Report
}

\author{
Gaurav Umesh Chaudhari1, Sumanthini Venkatsubramanyam Margasahayam², \\ Vanitha Umesh Shenoy ${ }^{3}$, Akash Kiran More ${ }^{4}$, Anuradha Bhausaheb Patil ${ }^{5}$ \\ 1, 2,3,4, 5 Department of Conservative Dentistry and Endodontics, \\ MGM Dental College and Hospital, Kamothe, Navi Mumbai, India.
}

\section{INTRODUCTION}

The goal of endodontic treatment is elimination of microorganisms from the infected root canals and prevention of further infection, which is achieved thorough cleaning and shaping of root canals followed by obturation and an adequate coronal restoration. ${ }^{1}$ In the event of intraradicular reinfection due to inadequacies of previous treatment, persistence of infection, or reinfection when the coronal seal is lost, retreatment is carried out. Retreatment is mainly based upon the patient's clinical presentation and compliance, operator's experience and expertise, the risk of complications, technical and economic feasibility. ${ }^{2}$ The treatment options could be nonsurgical retreatment, surgical retreatment, combined nonsurgical and surgical or extraction. ${ }^{3}$

Complete removal of gutta-percha from the root canal, re-establishing working length, promoting disinfection and re-obturating the root canal are the main goals of non-surgical retreatment in order to establish healthy periapical tissues. ${ }^{4}$ Loss of apical constriction due to resorption or over instrumentation often leads to overextension of obturating materials such as gutta-percha (GP) and root canal sealers. Residual GP in the periapical tissues may cause mechanical irritation and inflammation, thereby leading to endodontic failure. ${ }^{5}$ Most often the overextended GP section is removed by a surgical approach as they may not be amenable to orthograde removal. This case report describes the nonsurgical retreatment of a permanent maxillary central incisor with apically extruded GP.

\section{PRESENTATION OF CASE}

A 44 years old male patient reported to the Department of Conservative Dentistry and Endodontics with a chief complaint of discoloured upper anterior tooth observed by him for over a period of six months. Past dental history revealed that patient had undergone root canal treatment with respect to 11 , two years ago. On clinical examination there was no restoration seen in the access cavity. The concerned tooth was nonresponsive to thermal and electric pulp testing. Medical history was noncontributory. Gingival sulcus probing depth was within normal limits. Radiographic examination of the concerned tooth revealed a relatively well obturated root canal with GP seen extending beyond the root apex associated with a widened periodontal ligament space periapically [Fig 1]. Based on clinical and radiographic presentations, a diagnosis of previously root canal treated tooth with asymptomatic apical periodontitis in 11 was arrived at. The patient was offered three treatment options which were nonsurgical endodontic retreatment, periapical surgery or extraction followed by prosthetic replacement. The patient was averse to surgery and opted for non-surgical retreatment. He was further keen to preserve the existing crown, as he was satisfied with its function.
Corresponding Author:

Dr. Gaurav Umesh Chaudhari,

Chaudhari Chamber's, Faizpur,

Dist. Jagaon -425503, Maharashtra,

India.

E-mail: gv,chaudhari27@gmail.com

DOI: $10.14260 /$ jemds/2020/691

How to Cite This Article:

Chaudhari GU, Margasahayam SV, Shenoy $V U$, et al. Nonsurgical removal of overextended gutta-percha root canal filling in a permanent maxillary central incisor with apical root resorption: a case report. J Evolution Med Dent Sci 2020;9(42):3159-3162, 10.14260/jemds/2020/691

Submission 17-07-2020,

Peer Review 11-09-2020,

Acceptance 17-09-2020,

Published 19-10-2020.

Copyright (C) 2020 Gaurav Umesh Chaudhari et al. This is an open access article distributed under Creative Commons Attribution License [Attribution 4.0 International (CC BY 4.0)] 
After obtaining patient consent and local anaesthesia (LA) sensitivity testing, treatment was started. Under the rubber dam (Hygienic, Coltene / Whaledent Inc, USA) isolation, access cavity was cleansed of debris using a round diamond point (Mani INC. Japan) and irrigated copiously with normal saline (NS) (Influtec healthcare limited, Indore) and $2.5 \%$ sodium hypochlorite $(\mathrm{NaOCl})$ (Trifarma, Thane). Tentative working length of $19 \mathrm{~mm}$ was measured using the preoperative radiograph. The obturating material was observed to be GP. Coronal $2-3 \mathrm{~mm}$ of GP was removed using heated hand pluggers (GDC Fine Crafted Dental Pvt. Ltd. Hoshiarpur) while middle and apical extent was removed using a combination of $0.5 \mathrm{~mL}$ of GP solvent (G SOL, Maarc Dental, India) and \#15, 20 and $25 \mathrm{H}$ files (Mani INC. Japan). After removal of obturating material from the canal, radiographs were taken for confirmation of GP removal [Fig. 2].

The radiographs revealed the extruded GP beyond the apex. In order to remove the GP, $0.1 \mathrm{~mL}$ of solvent was introduced into the canal, an unused new sterile \#25 H-file was gently precurved and inserted into the canal 0.5 to $1.0 \mathrm{~mm}$ beyond the apical foramen and was made to engage the GP while rotating clockwise. Then the file was gently but firmly withdrawn away from the dentinal wall during retrieval. If the file failed to retrieve the GP, the same procedure was repeated using a large number $30 \mathrm{H}$-file. Gutta-percha solvent was not used for retrieval of the overextended fragment. The procedure was followed by copious irrigation with NS using a side vented needle (Prime dental products PVT LTD, India). During irrigation it was observed that GP fragments floated out of the canals in small increments. Radiographs were taken for confirmation of GP removal [Fig. 3].

The root canal was explored and initial apical binding file was a no. $80 \mathrm{k}$-file (Mani INC. Japan) and the working length of $19 \mathrm{~mm}$ was established electronically and confirmed radiographically [Fig. 4].

Cleaning and shaping was accomplished with gentle circumferential filing with a size $60 \mathrm{H}$-file. The root canals were intermittently irrigated with $20 \mathrm{~mL}$ of $2.5 \%$ sodium hypochlorite $(\mathrm{NaOCl})$ (Trifarma, Thane). Passive ultrasonic irrigation (PUI) was performed for 3 cycles of 20 sec duration each cycle using Irrisafe tip size \#25 (Satelecacteon, France). After every cycle of $20 \mathrm{sec}$ duration, the canal was flushed with $2.5 \% \mathrm{NaOCl}$. This procedure was followed by NS, $2 \%$ Chlorhexidine (CHX) $5 \mathrm{~mL}$ (Neelkant health care, Jodhpur) and finally flushed with NS. A dense paste of calcium hydroxide (CH) (Deepti Dental product, India) and saline was placed in the root canal. The access cavity was temporized with cotton pledget and zinc oxide eugenol cement (Prime dental products PVT LTD, India) for a period of 2 weeks.

As the apical third gauging size was \#80 K-file due to loss of apical constriction, extrusion of obturating material was imminent. Hence placement of a Mineral trioxide aggregate (MTA) apical plug was decided. On the consecutive visit, the canal was re-accessed, and $\mathrm{CH}$ dressing was removed using $\mathrm{NaOCl}$ irrigation and $\mathrm{H}$-files followed by PUI using Irrisafe tip size 25. Irrigation was done with 3 cycles of 20 sec activation and flushed with NS which resulted in a total of 1 minute of activation. The root canal was finally irrigated with $5-10 \mathrm{~mL}$ of $2.5 \% \mathrm{NaOCl}$ followed by NS and $5 \mathrm{~mL}$ of $2 \%$ CHX. Smear layer was removed with $1 \mathrm{~mL}$ of $17 \%$ EDTA for 1 minute followed by $5 \mathrm{~mL}$ of $2.5 \%$ sodium hypochlorite. Following final irrigation, a hand plugger (GDC Fine Crafted Dental Pvt. Ltd.
Hoshiarpur) passively fitting $1 \mathrm{~mm}$ short of working length was selected. The canal was dried using absorbent points (Dentsply Maillefer instruments holding S.A.R. Switzerland). MTA (PROROOT Dentsply, Delhi) was mixed with sterile water in a ratio of $3: 1$ on a sterile glass slab, and the mix was carried to the root canal in increments with a sterile MTA carrier (GDC Fine Crafted Dental Pvt. Ltd. Hoshiarpur). First increment of MTA was carried to the desired working length with premeasured absorbent point in a vibrating motion and condensed with pre measured plugger. Subsequently, three more increments of MTA were placed to form an apical plug of $5 \mathrm{~mm}$ and was confirmed radiographically [Fig. 5]. After the second increment, MTA was compacted by applying indirect ultrasonics to the hand pluggers for a period of 5 seconds. A moistened cotton pledget was placed in the root canal space and access cavity was temporized with IRM (Dentsply, Germany). Further treatment would be continued with post placement followed by crown prosthesis.

\section{DISCUSSION}

For successful healing, all the root canal treatment procedures and obturating material should terminate at the apical constriction which is 0.5 to $1 \mathrm{~mm}$ from the radiographic apex. ${ }^{6}$ In the present case report GP was seen extending beyond the radiographic root apex. Gutta-percha is generally well tolerated by the periapical tissues and does not elicit an inflammatory response. ${ }^{7}$ However, often apical seal is found to be defective in overfilled canals. This causes percolation of tissue fluids which could provide nutrients for residual microorganisms to multiply resulting in persistent periapical lesion. ${ }^{8}$ Compounded to this was the absence of coronal restoration. In their study, Ray \& Trope (1995) observed that, the quality of the coronal restoration was far more essential for the periapical healing than the quality of the endodontic treatment. ${ }^{9}$ Root canal systems can be re-contaminated if the coronal seal is defective. ${ }^{10}$ Endodontically treated teeth without coronal restoration were found to have bacterial toxins at the root apex after 3 weeks. ${ }^{11}$ Thus studies have suggested that coronal leakage may be far more important than apical leakage for determining clinical success or failure. ${ }^{10}$

Though the obturation of the tooth involved was apparently satisfactory in spite of an overfilling, endodontic retreatment was done due to loss of coronal seal. Generally, surgical technique is indicated to remove the overextended material however a nonsurgical method is conservative, safe and has shown satisfactory long-term healing. ${ }^{12} \mathrm{~A}$ high percentage of nonsurgical endodontic therapy has been shown to have resulted in complete or partial healing of periapical lesions. ${ }^{13,14}$

During nonsurgical retreatment, the root canal filling material can be removed with K-files, H-files, rotary files, rotary retreatment files in combination with GP solvent, heat transfer devices, heat carrier tips, ultrasonic tips and soft tissue lasers. ${ }^{15}$ The overextended GP in the case presented was retrieved using $\mathrm{H}$-files in combination with a chemical solvent by non-surgical orthograde technique described previously by Metzger and Ben-Amar to retrieve overextended GP in endodontic treatment failure cases. ${ }^{16}$ 


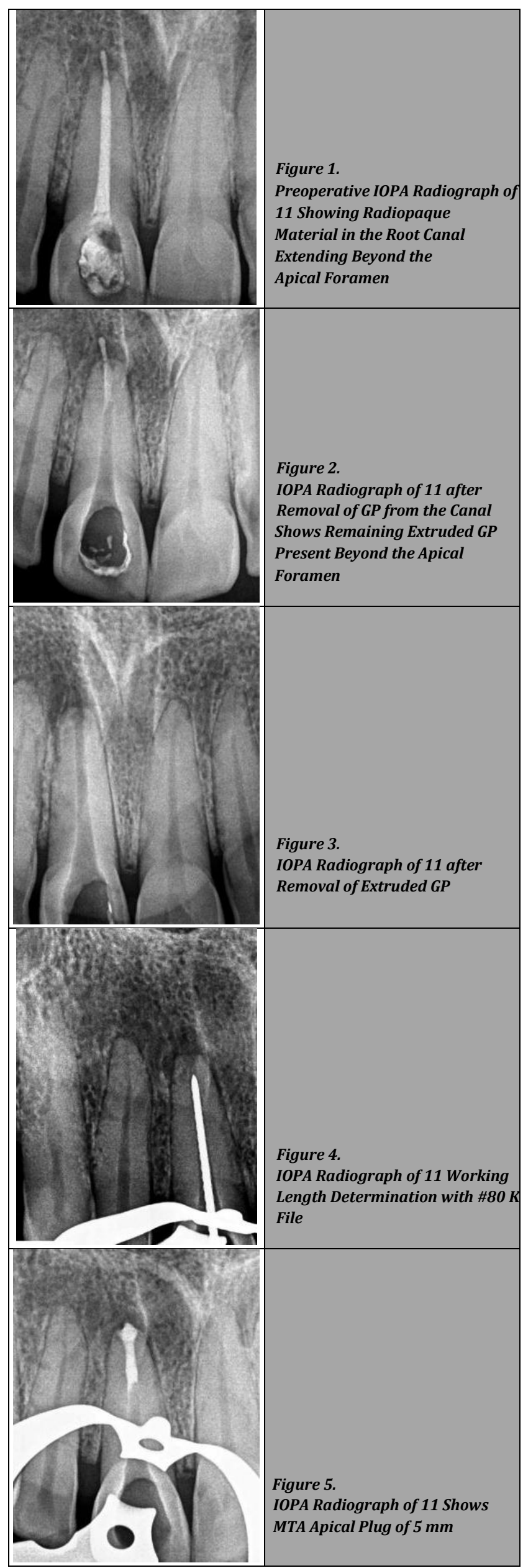

Initially the GP was softened by xylene as it evaporates to a lesser degree and takes more time to infiltrate the GP.16 Gutta-percha solvents should not be used copiously to soften the overextended fragment, because this can result in nonengagement of overextended fragment by $\mathrm{H}$-file and thus hindering in its retrieval. ${ }^{3}$ Furthermore, they may also be pushed more periapically negating any ortho grade removal. $\mathrm{H}$-files are preferable to remove due to its high cutting efficiency, because it has a more positive rake angle and a blade with a cutting rather than a scraping angle working area configuration which helps in engaging the GP and mobilize it coronally. ${ }^{17}$

The root canal space was intermittently irrigated with CHX as studies have reported that in retreatment cases chlorhexidine gluconate irrigation was effective against Enterococcus faecalis. ${ }^{18}$ This is the most frequently associated bacteria with failed root canal treated teeth and asymptomatic chronic periradicular lesions. 18,19

The root canal was disinfected with intracanal medication of $\mathrm{CH}$ saline paste after thorough cleaning shaping. The antimicrobial effect of $\mathrm{CH}$ is associated with hydroxyl ion release in an aqueous environment, which is detrimental to cytoplasmic membranes, proteins and the DNA of microorganisms. Calcium hydroxide has a wide range of antimicrobial activity against microorganisms prevalent in the root canal. ${ }^{20}$

PUI improves the efficacy of endodontic irrigants like $\mathrm{NaOCl}$ and EDTA. This results in better removal of microorganisms, dentinal debris, organic tissue remnants and smear layer a by increasing the reaction rate of irrigants so that they are absorbed or dissolved in the irrigant. ${ }^{21}$

The loss of apical constriction due to apical root resorption and wide canal leads to extrusion of GP from the confines of the root canal space. Thus, apexification with MTA was planned as it has shown promising results as a material suitable for single visit apexification due to its biocompatibility and with optimum sealing ability as a root end filling material.22 MTA forms an apical barrier in teeth with necrotic pulp and open apices that permits vertical condensation of warm GP. When MTA is placed in direct contact with human tissues, it forms calcium hydroxide. This results in formation of calcium ions which is essential for cell attachment and propagation, antibacterial effect by its high alkaline $\mathrm{pH}$, modulate cytokine secretion, encourages differentiation and migration of osteoblast like cells, forming hydroxyapatite on the MTA surface and provides a biologic seal. ${ }^{23}$ The setting of MTA is not affected by the presence of blood or tissue fluids. ${ }^{24}$ The required moist condition for setting is achieved by a moist cotton pellet placed temporarily in direct contact with the MTA plug or the surrounding tissues and sealed adequately with an interim restoration for at least twenty four hours. ${ }^{25}$

The cause for failure of primary endodontic treatment are mainly microbiological. Several treatment options have been suggested. The rationale for retreatment has to be essentially based on sound mechanical and biological objectives directed towards elimination of infection from the root canal system. 


\section{CONCLUSIONS}

Nonsurgical retreatment procedures in failing root canal treated teeth have shown a high success rate and therefore should be the preferred choice initially. The technique illustrated to retrieve the periapically overextended GP is conservative and reliable. Furthermore, successful endodontic treatment outcomes depend on adequate coronal and apical seal.

Financial or other competing interests: None.

Disclosure forms provided by the authors are available with the full text of this article at jemds.com.

\section{REFERENCES}

[1] Al-Ali MM, Al-Ibrahim AM, Al-Ali SM. Current trends in irrigation practice during endodontic treatment among general dental practitioners in Saudi Arabia. Saudi Endod J 2018;8(3):170-5.

[2] Del Fabbro M, Taschieri S, Testori T, et al. Surgical versus non-surgical endodontic re-treatment for periradicular lesions. Cochrane Database Syst Rev 2007;3:CD005511.

[3] Stabholz A, Friedman S. Endodontic retreatment --case selection and technique. Part 2: treatment planning for retreatment. J Endod 1998;14(12):607-14.

[4] Somma F, Cammarota G, Plotino G, et al. The effectiveness of manual and mechanical instrumentation for the retreatment of three different root canal filling materials. J Endod 2008;34(4):466-9.

[5] Swartz DB, Skidmore AE, Griffin JA. Twenty years of endodontic success and failure. J Endod 1983;9(5):198202.

[6] Cohen S, Burns RC. Pathways of the pulp. 10 $0^{\text {th }}$ edn. St. Louis: CV Mosby 2011:910-12.

[7] Witherspoon DE, Gutmann JL. Analysis of the healing response to gutta-percha and Diaket when used as rootend filling materials in periradicular surgery. Int Endod J 2000;33(1):37-45.

[8] Sritharan A. Discuss that the coronal seal is more important than the apical seal for endodontic success. Aust Endod J 2002;28(3):112-5.

[9] Ray HA, Trope M. Periapical status of endodontically treated teeth in relation to the technical quality of the root filling and the coronal restoration. Int Endod J 1995;28(1):12-8.

[10] Oliver CM, Abbott PV. An in vitro study of apical and coronal microleakage of laterally condensed gutta percha with Ketac-Endo and AH - 26. Aust Dent J 1998;43(4):2628.
[11] Torabinejad M, Ung B, Kettering JD. In vitro bacterial penetration of coronally unsealed endodontically treated teeth. J Endod 1990;16(12):566-9.

[12] Gupta S, Dhiman M, Mehta M. Non-surgical removal of overextended gutta-percha in endodontic retreatment cases. Int J Health Sci Res 2015;5(11):389-91.

[13] Murphy WK, Kaugars GE, Collett WK, et al. Healing of periapical radiolucencies after nonsurgical endodontic therapy. Oral Surg Oral Med Oral Pathol 1991;71(5):6204.

[14] Bender IB. A commentary on general Bhaskar's hypothesis. Oral Surg Oral Med Oral Pathol 1972;34(3):469-76.

[15] Jaikailash S, Kavitha M, Gokul K. Nonsurgical removal of separated gutta percha and granulation tissue from the periapical area using an aspiration irrigation technique. SRM J Res Dent Sci 2012;3(3):220-3.

[16] Metzger Z, Ben-Amar A. Removal of overextended guttapercha root canal fillings in endodontic failure cases. J Endod 1995;21(5):287-8.

[17] Chandra BS, Gopikrishna V. Shaping and cleaning of the radicular space: instruments and techniques. In: Chandra BS, Gopikrishna V, eds. Grossman's endodontic practice. $13^{\text {th }}$ edn. New Delhi: Wolters Kluwer Pvt Ltd 2014:287321.

[18] Rôças IN, Siqueira JF, Santos KRN. Association of Enterococcus faecalis with different forms of periradicular diseases. J Endod 2004;30(5):315-20.

[19] Ohara P, Torabinejad M, Kettering JD. Antibacterial effect of various endodontic irrigants on selected anaerobic bacteria. Endod Dent Traumatol 1993;9(3):95-100.

[20] Kim D, Kim E. Antimicrobial effect of calcium hydroxide as an intracanal medicament in root canal treatment: a literature review - Part I. In vitro studies. Restor Dent Endod 2014;39(4):41-52.

[21] van der Sluis LW, Versluis M, Wu MK, et al. Passive ultrasonic irrigation of the root canal: a review of the literature. Int Endod J 2007;40(6):415-26.

[22] Shabahang S, Torabinejad M. Treatment of teeth with open apices using mineral trioxide aggregate. Pract Periodontics Aesthet Dent 2000;12(3):315-22.

[23] Parirokh M, Torabenejad M. Mineral trioxide aggregate: a comprehensive literature review - part III: clinical applications, drawbacks and mechanism of action. J Endod 2010;36(3):400-13.

[24] Torabinejad M, Higa RK, McKendry DJ, et al. Dye leakage of four root end filling materials: effects of blood contamination. J Endod 1994;20(4):159-63. 